\title{
Pandemic (H1N1) 2009 Influenza: Bangladesh Perspective
}

Over the last couple of decades the world has observed the emergence and re-emergence of a number of infectious diseases along with a surge of noncommunicable diseases. The recent report published in a local daily following a scientific round table conference claimed that a new infectious disease entity is seen in the face of the earth every eight months. ${ }^{1}$ In current context the report has got an enormous impact. Within a very short period of time we have seen that SARS and Avian Influenza (Bird Flu) devastated life globally. For long, bacterial infections had been the mainstay of concern for the medical community. With appropriate advancement of anti-bacterial therapy it has been possible to restrain these organisms till the reemergence of Multi Drug Resistant (MDR) strains. Dealing with viral diseases has been a real challenge. Although a limited number of anti-viral agents are available, the appropriate measure to control and treat viral infections is the 'wait and see' approach: Whereby we provide supportive measures and wait for the body to eliminate the offending viruses through activation of its own immune system.

The recent outbreak of Pandemic Influenza H1N1 2009 , is a newly packaged form of the good old Influenza A virus. It's a triple reassortment virus: Which means that it is a combination of the Classical Swine H1N1, Human H3N2 and Avian influenza viruses known as the North American Swine H3N2 and H1N2 that later converted into the 2009 Human H1N1 virus. Direct transformation of Classical Swine H1N1 has also taken place. The whole process has resulted in a very fast human to human transmission of these influenza viruses giving rise to a pandemic.

Infection of the respiratory tract leads to production of cytokines which damages the respiratory epithelium. In a few number of cases, depending on age and associated comorbidities the viral infection culminates into development of severe pneumonia, which is the main cause of death. ${ }^{2}$
In late April, 2009 the outbreak started in Mexico and up to the $11^{\text {th }}$ of September, 2009 there were 277,607 confirmed cases throughout the world with 3,205 deaths. ${ }^{3}$ Out of this 22,387 cases were from the SEARO (South East Asian Region) where 221 died. In India alone there were 6,143 cases along with 176 deaths. ${ }^{4}$ According to the report published on the $21 \mathrm{st}$ of September by the Director General of Health Services of the Government of India the total number of confirmed cases increased to 8,153 with 257 deaths within a span of 10 days. ${ }^{5}$ All this data were prior to level 3 WHO alert, from which point onwards lab confirmation was not required for antiviral treatment. It means that the true number is much more than what has been reported. The number of lab confirmed cases in Bangladesh stood at 372 with death of 3 cases till the $13^{\text {th }}$ of September, 2009. ${ }^{6}$ Currently lab confirmation is no longer required in Bangladesh as well. 'Flu Corner' and 'Flu Ward' has been made fully operational in the tertiary care hospitals of the country along with Bangabandhu Sheikh Mujib Medical University (BSMMU) and a number of private hospitals in Dhaka. The 'Flu corner' of Dhaka Medical College Hospital treated 2226 cases with flu or flu like symptoms during this period. Out of them 28 cases from these were admitted to the flu ward where 10 cases tested positive. According to Institute of Epidemiology Disease Control \& Research (IEDCR) the predominant flu strain active in this season is the H3N2. ${ }^{6}$ Since the features of both these viral strains are similar they have led to much confusion regarding which form a patient is suffering from. Distinguishing them is often difficult. In both the cases isolation and supportive management is the key treatment procedure. Recently a guideline for management of Pandemic Influenza H1N1 - 2009 in Bangladesh has been formulated and made available which states the do's and don'ts along with appropriate management protocols and clear indication for the use of antiviral therapy. ${ }^{7}$ This has 
made things easier for the physicians regarding decision making.

A well formulated preventive strategy has also been undertaken by the Government of Bangladesh. Health support desk was started in 15 ports along with ZIA international airport. ${ }^{5}$ All secondary and tertiary level hospitals have been provided with adequate storage of Oseltamivir and trained staff to combat the emergency. Thirty district hospitals have complete isolation units and the rest will have the units by the end of the year. The Government has a stock of 240,000 courses of Oseltamivir till date. ${ }^{6}$

The closure of schools and educational institutes is a controversial issue. The WHO has no proper guideline regarding when to take such a decision. Rather they have left the whole matter for the local authorities to decide. The pros and cons are described in their guideline. ${ }^{8}$ On one hand closing schools at an appropriate time may restrict disease spread on the other hand the economical burden and panic created is enormous when such a decision is taken. The major consideration should be whether it would limit contact among students when they are not in school. In an over crowded country like Bangladesh, the possibility of limiting contact from school absenteeism is quite unlikely.

According to the WHO this is only the first wave of Pandemic Influenza H1N1 - 2009 the second wave is yet to come. The only measure to stop this is to vaccinate people. United States Food and Drug Administration (US-FDA) has approved an effective vaccine on the $15^{\text {th }}$ of September, 2009 and provided manufacturing license to four companies. ${ }^{9}$ Initially it was thought that two shots will be required for effective immunization. China first came up with the proof that in fact a single shot is good enough. ${ }^{10}$ This was accepted by the medical faculty world wide. As a result both time and cost have come down to half. Centers for Disease Control and Prevention (CDC) has prepared a recommendation regarding who should receive the vaccine. ${ }^{11}$ The initial recipients would be pregnant women, household contacts and caregivers for children younger than 6 months of age, healthcare and emergency medical services personnel and all people from 6 months to 24 years of age. Persons aged from 25 to 64 years who have associated health condition with higher risk of medical complications from influenza have also been included in the recipient group. These were the most vulnerable group during the first attack in terms of acquiring the disease, mortality and morbidity. The rest will also be vaccinated when sufficient vaccine comes in hand. United States of America in conjunction with Australia, Brazil, France, Italy, New Zealand, Norway, Switzerland and United Kingdom has announced the donation of pandemic vaccine to the developing nations. ${ }^{12}$ This will ensure an equal share of the currently limited amount of vaccines for the poor nations. So it is important for us to formulate a strategy regarding vaccination by identifying priority groups based on susceptibility. This will ensure proper utilization of the limited amount of vaccine that we will receive in the first batch.

So far we have been able to control our part of this pandemic quite satisfactory. The number of cases and casualties is well within the tolerable range. To ensure that things remain as good as it is now we have to keep up the vigilance and modify the measures well in time to overcome new situations.

\section{H A M Nazmul Ahasan}

FCPS, FRCP, FACP

Professor, Department of Medicine, Dhaka Medical College

(J Bangladesh Coll Phys Surg 2009; 27: 129-131)

\section{Reference:}

1. Mondol, Shishir. [Risk of a new disease every eight months]. Available at: www.prothom-alo.com/newsite1/ detail/date/2009-09-19/news/6883 Accessed September 24, 2009.

2. Perez-Padilla R, de la Rosa-Zamboni D, Ponce de Leon S, et al. Pneumonia and respiratory failure from swine-origin influenza A (H1N1) in Mexico. N Engl J Med 2009;361:680-9.

3. World Health Organization. Situation report-Pandemic H1N1 2009 (13 September, 2009). www.whoban.org/ pdf/SitRep_A_(H1N1).pdf Accessed September 24, 2009.

4. World Health Organization. Summary of Situation of Pandemic H1N1 2009 for week of 7 - 13 September 2009. Available at: www.searo.who.int/EN/ Section10/ Section2562_15050.htm Accessed September 24, 2009.

5. Directorate General of Health Services, Government of India. Consolidated status of influenza A H1N1: 21 
September 2009. Available at: mohfw.nic.in/ press releases on_swine_flu.htm Accessed September 24, 2009.

6. Institute of Epidemiology, Disease Control and Research Influenza A H1N1 (Swine Flu) Fact Sheet (updated on 1609-2009). Available at: www.iedcr.org Accessed September 24, 2009.

7. Institute of Epidemiology, Disease Control and Research. Treatment Guideline for Influenza A H1N1 (updated on 1908-2009). Available at: www.iedcr.org/images/PDF/ Treatment_guideline.pdf Accessed September 24, 2009.

8. World Health Organization. Measures in school settings. Available at: www.who.int/csr/disease/ swineflu/notes/ h1n1_school_measures_20090911/en/index.html Accessed September 24, 2009
9. Neergaard L. FDA Approves Swine Flu Vaccine. Associated Press. Available at: news.aol.com/health/article/fda-approvesswine-flu-vaccine/446911 Accessed September 24, 2009.

10. Schmid RE, Cheng M. China approves single-dose swine flu vaccine. Associated Press. Available at: www.physorg.com/ news171178203.html Accessed September 24, 2009.

11. Centers for Disease Control and Prevention. 2009 H1N1 Vaccination Recommendations. Available at: www.cdc.gov/ h1n1flu/vaccination/acip.htm Accessed September 24, 2009.

12. World Health Organization. Pandemic vaccine donations for the developing world. Available at: www.who.int/ mediacentre/news/statements/2009/pandemic_vaccine_donat ions 20090918/en/index.html Accessed September 24, 2009. 